\title{
Método de Benjamin Constant de Rebecque para o Estudo do Fenômeno Religioso em De la Religion ${ }^{1}$
}

\section{Benjamin Constant de Rebecque's Method for the Study of Religious Phenomenon in De la Religion}

Marco Antônio Barroso*

Resumo

\begin{abstract}
A hermenêutica apresentada por Constant de Rebecque consistiria em se arriscar no terreno da teologia do seu tempo em lugar de formular uma estrutura argumentativa puramente histórica para a descrição do fenômeno religioso. As finalidades da pesquisa de Constant em De la religion são: 1) escrever uma obra sobre as religióes em geral e, em especial, sobre as religióes antigas, para analisar o que é o fato religioso em suas manifestações (históricas, sociológicas e políticas); 2) descrever o que é o sentimento religioso em sua essência. Neste segundo caso, trata-se, pois, de demonstrar que a religiosidade, ou o sentimento religioso, é um dos fundamentos da individualidade. Para o nosso autor, este sentimento, enquanto disposição humana, sempre ativa, perfectível e percebida de forma individual, serve como referência para o que é a "verdadeira religião" e também para liberdade.
\end{abstract}

Palavras-chave: Constant de Rebecque, sentimento religioso, método.

Recebido em 30/12/2013. Aprovado em 06/05/2014

Possui Licenciatura (2005) e Bacharelado (2006) em Filosofia pela Universidade Federal de Juiz de Fora; Especialização (2006), Mestrado (2009) e Doutorado (2013) em Ciência da Religiâo, área de concentraçấo Filosofia da Religiấo, pela mesma instituição. É professor e pesquisador da UEMG/Unidade de Ubá desde 2011, onde atua nas áreas de Filosofia e História das Ciências e Ética. E-mail: marco.barroso78@gmail.com 
The hermeneutics presented by Constant de Rebecque would consist in venturing into the field of theology in his time instead of formulating a purely historical argumentative structure for describing religion's social phenomenon. Constant's research goals in De la religion are: 1) write a piece about religions in general, and in particular, about the ancient religions, to analyze what is the religious fact in its manifestations (historical, sociological and political); 2) describe what is the religious sentiment in its essence. In the latter case, it is therefore to demonstrate that religiosity, or the religious sentiment, is one of the cornerstones of individuality. For our author this sentiment, as human disposition, always active, perfectible and perceived individually, serves as a reference for what is the "true religion" and for freedom.

Keywords: Constant Rebecque, religious sentiment, method.

As finalidades da pesquisa de Benjamin Constant de Rebecque, em De lareligion, são duas: 1) escrever uma obra sobre as religióes em geral e, em especial, sobre as religióes antigas, para analisar o que é o fato religioso em suas manifestaçôes (históricas, sociológicas e políticas); 2) descrever o que é o sentimento religioso em sua essência. Neste segundo caso, trata-se, pois, de demonstrar que a religiosidade, ou o sentimento religioso, é um dos fundamentos da individualidade. Para o nosso autor, é ele que, enquanto disposição humana, sempre ativa, perfectível e percebida de forma individual, serve como referência do que é a "verdadeira religião" e também da própria liberdade. A respeito do conhecimento do fenômeno religioso, frisa Wach, mais de um século depois, que "em oposiçáo à preocupação popular relativa à função da religião, é preciso insistir na investigação de sua natureza." (Wach, 1967, p. 96) ${ }^{1}$.

A hermenêutica apresentada pelo nosso autor consistiria em se arriscar no terreno da Teologia do seu tempo em lugar de formular uma estrutura argumentativa puramente histórica para a descrição do fenômeno religioso (como havia planejado inicialmente). De acordo com Kloocke, Constant assumiu o ponto de vista da

"En oposición con la preocupación popular relativa a la función de la religión, es preciso insistir em la investigación de su naturaleza”. 
neologia, uma linha de interpretação teológica que postula que a revelação da verdade religiosa está ligada diretamente ao progresso das luzes. Segundo essa ideia, "a história não decide a superioridade de uma religião em relação à outra, mas pode servir para demonstrar a depuração progressiva do pensamento religioso. A história é concebida sob a forma de revelação contínua da Divindade, pelo trabalho espiritual do homem; a história é o terreno da revelação." (Kloocke, 1996, p. 396). ${ }^{2}$

Caberia, pois, à Hermenêutica colocar em evidência a relação história/revelação, abrindo a possibilidade de interpretação da religiosidade, assim como ela se manifesta para o homem moderno tal como concebe Constant, uma religião calcada na individualidade e como manifestação da liberdade. Sob essa nova chave de leitura, os fatos históricos ainda teriam um grande valor, porque eles serviriam como base da qual se partiria a racionalização possível a respeito do fenômeno religioso. Mas em primeiro lugar viria o raciocínio filosófico teológico, "para fazer a análise crítica de seu significado, para a demonstração de uma hipótese teológica que vai contra o dogmatismo e tenta estabelecer o conceito de liberdade espiritual interior." (Kloocke, 1996, p. 397) 3 .Ainda a respeito da hermenêutica constantiniana, afirma Kloocke (1996, p. 402):

Os conceitos hermenêuticos de Constant obedecem à necessidade de analisar os materiais, extrair deles uma teoria coerente, em que a ideia mestra é definir o espírito da religião, que se manifesta através da história das religióes. Deve-se sempre, como em Montesquieu, sublinhar em um caso particular a significação geral, e dar à diacronia aparente da série fetichismo-politeísmo-teísmo uma significação simbólica e metodológica. ${ }^{4}$

"Par conséquente l'histoire ne décide pas de la supériorité d'une religion par rapport à une autre, mais peut servir à démontrer l'épuration progressive de la pensée religieuse. L'histoire est conçue sous la forme d'une révélation continuelle de la divinité par le travail spirituel de l'homme; elle est le terrain de la révélation".

"A la critique des faites, à lanalyse de leur signification, pour la démonstration dıune hypothèse théologique qui dirige contre tout dogmatisme et essaie d'établir la notion de une liberté spirituelle intérieure."

"Les conceptes hermeneutiques de Constant obéissent au besoin dranalyser les matérieux pour en degager une théorie cohérente dont lidée maîtresse est definir l’esprit de la religion que se manifeste à travers lhistoire des religions. Il doit toujours, comme Montesquieu, souligner 
Depreende-se do escrito até aqui os principais aspectos da hermenêutica formulada por Constant: a) Em primeiro lugar, surge a hipótese do sentimento religioso como uma constante antropológica, comparável à sociabilidade e à linguagem; b) é destacada a constatação de que as religióes positivas são as manifestaçóes concretas - porém, instáveis - do sentimento religioso, objetos de uma história das religiôes (historiografia impraticável); c) é lembrada a necessidade de construir uma teoria do sentimento religioso para demonstrar sua perseverança e autonomia, em todas as épocas da humanidade, apesar da forma passageira que reveste esse sentimento. Nessa perceptiva, a história das religióes é a outra face da teoria geral do sentimento religioso.

Segundo Kloocke (1996, p. 403),

a grande descoberta metodológica de Constant consiste em substituir a impossível totalidade do quadro histórico por uma demonstração sistemática. A prática sintética coloca em obra descriçôes estereotipadas e sintetizantes, que substituem a incômoda totalidade dos materiais históricos. Estas descriçôes são estruturalistas, no sentido de que elas emitem o significado geral de fatos históricos, elas são, por assim dizer, o significante de um complexo de significados com um certo grau de variação. ${ }^{5}$

Já no prefácio de De la religion, encontramos sinalizadas as temáticas que serão abordadas ao longo de toda a obra. Localizamos, também, indícios que apontam as novidades metodológicas utilizadas pelo autor. O problema central do primeiro tomo de De la religion é, segundo o autor, estabelecer noçôes sobre os elementos que compóem o culto dos selvagens e demonstrar sua consolidação nas antigas religiôes sacerdotais - especialmente as do Egito, da Índia e da Gália. Sem descartar os "conhecimentos profundos" dessas

dans un cas particulier la signification générale, et donner à diachronie apparente de la série fétichisme-polythéisme-théisme une signification symbolique ou méthodologique".

"La grand découverte méthodologique de Constant est de remplacer l'impossible totalité de tableau historique par une démonstration systématique. La pratique synthétique mise en œuvre descriptions stéréotypés et synthétisant qui remplacent l'encombrante totalité des matériaux historiques. Ces descriptions sont structuralistes dans ce sens qu'elles dégagent les significations générales des faits historiques, qu'elles sont pour ainsi dire le signifiant d'un signifié complexe avec une certaine marge de variations ». 
antigas religióes, ele anuncia que seu foco principal será o papel do sacerdote na constituição daquelas instituiçóes. Constant afirma que, ao contrário das denominadas de grandes religióes (judaísmo, cristianismo, islamismo, budismo, etc.), na religiâo grega, a figura do sacerdote como personagem central da organização religiosa só teria um aparecimento tardio e por influência dos povos que travavam comércio com o mundo helênico, já em seu ocaso.

Percebemos a constante procura do rigor metodológico pelo autor, porque náo deseja que a obra de sua vida seja recebida pelo público leitor como mais uma "obra de erudição". Como ferramenta para proporcionar a possibilidade do estudo comparado de um elemento constitutivo de diversas culturas, o autor cria um tipo ideal, o sacerdote, antecipando aquilo que mais tarde faria Weber na construção de seu método sociológico ${ }^{6}$.

Ainda no prefácio do livro, encontramos outra passagem que ressalta a busca do escritor franco-suíço por uma posiçáo metodológica "neutra" para o estudo do fenômeno religioso. Conforme escreve o próprio Constant (1999, p. 28):

Nossa censura contra o sacerdócio de alguns politeísmos foi mesmo bem menos amarga que o julgamento efetivado contra eles pelos padres da Igreja ou pelos teólogos que marcharam sobre seus rastros. [...]; nós indicamos o bem relativo que poderiam fazer os ministros de um culto errôneo, porque, por via do sentimento religioso, o erro, em nossa opinião, é melhor que a omissão.?

Nesta citação, encontramos em De la religion, pela primeira vez, o conceito de sentimento religioso. Conforme veremos à medida que aprofundarmos nessa ideia, esse sentimento seria, assim como o sentimento de liberdade, algo constitutivo do ser humano,

Sobre o tema Cf. Kloocke, Kurt, 1984, p.79, nota 70 ; 2003, p. 157, confrontar especialmente nota 50 , onde Kloocke estabelece uma interessante relação entre Constant, Schleiermacher e Weber.

"Notre censure contre le sacerdoce de quelques polythéismes a été même bien moins amère que le jugement porté contre lui par les pères de l'église ou par les théologiens qui ont marché sur leurs traces. [...]; nous avons indiqué le bien relatif qu'ont pu faire les ministres d'un culte erroné, parce que, en fait de sentiment religieux, l'erreur, à notre avis, vaut mieux que l'absence." 
segundo Constant. Ele seria, pois, o "motor" do fenômeno ao qual denominamos religião, em todas as épocas da humanidade. Sendo ele mesmo atemporal, sua forma é determinada pelo contexto sóciohistórico no qual se manifesta - não cabendo julgar, a princípio, sua participação na constituição da moral. E, à medida que os meios físicos se aperfeiçoam, este sentimento encontra novas formas de expressão, refinando as religióes instituídas. Para nosso autor, o sentimento religioso não determina, por si só, as açôes morais de um indivíduo ou de uma sociedade; embora ele seja o mais nobre e correto elemento fundante da moral, não é o único. Infere-se daí que os sacerdotes de cada religião primitiva fizeram o melhor que lhes era permitido fazer no contexto em que se encontravam, acontecendo a maior parte de seus erros por limitaçóes impostas por fatores históricos.

É no primeiro capítulo do livro De la religion que Constant trata do conceito de sentimento religioso (sentimentreligieux). É interessante notar que o autor começa esse capítulo fazendo uma clara referência a Montesquieu, dando razão à afirmativa que diz: "todos os seres vivos têm suas leis". Para conhecermos as leis, frisa Constant, não é necessário distinguirmos as causas primordiais, mas é imprescindível partir do reconhecimento de sua existência para explicar os fenômenos. É preciso ser imparcial e vê-las como um fato, sobre o qual náo nos compete contestar a realidade e do qual nos importa somente saber sua natureza e captar suas modificaçóes sucessivas.

Essas leis, por sua vez, "constituem a natureza de cada espécie", elas são a "causa geral e permanente do modo de existência de cada uma; e quando algumas causas externas trazem alguma mudança parcial a este modo de existência, o fundo resiste e reage sempre contra as modificaçóes." (Constant de Rebecque, 1999, p. $40)^{8}$. Como exemplo, o autor apresenta as variaçóes de instinto que caracterizam cada espécie animal; esses impulsos são uma "disposição que os caracteriza e que decide seus modos de existir".

"Cause générale et permanent du mode d'existence de chacune; et lorsque des causes extérieures apportent quelque changement partiel à ce mode d'existence, le fonde résiste et réagit toujours contre les modifications". 
O sentimento religioso seria, então, uma dessas leis. A esse respeito, escreve Constant (1999, p. 40): "se há, então, no coração do homem um sentimento que é estranho ao resto dos seres vivos e que sempre se reproduz, qualquer que seja a posição onde o homem se encontre, não é provável que este sentimento seja uma lei fundamental de sua natureza?" . Mais à frente, complementa: "este sentimento se associa, porém, a todas as nossas necessidades, a todos os nossos desejos" (Constant de Rebecque, 1999, p. 40) ${ }^{10}$. E logo depois encontramos a seguinte afirmação: "o sentimento religioso é uma emoção do mesmo gênero de todas as nossas emoçôes naturais; e consequentemente está sempre de acordo com elas" (Constant de Rebecque, 1999, p. 59). ${ }^{11}$

Atribuir ao medo, à ignorância ou ao poder as causas do surgimento da religiáo seria um erro. À medida que o conhecimento do homem sobre a natureza aumenta, e o temor dos fenômenos naturais é vencido, "os ensinamentos da experiência colocam a religiáo num outro terreno, mas não a bane do coração do homem"(Constant de Rebecque, 1999, p. 41) ${ }^{12}$. Ou seja, tal como entende Constant, o temor e a admiraçáo que o ser humano possui pela natureza sáo apenas "matérias" passageiras das quais o sentimento religioso se reveste para sua manifestação.

Indaga Constant, de forma retórica: se a religião está no fundo da alma de todos, de onde vem a oposiçáo de alguns a esse sentimento unânime? Segundo a argumentação desenvolvida pelo próprio autor, ao longo do tempo, a sociedade "desnatura" a religiáo - entendida como a forma de expressão do sentimento religioso. Este sentimento se manifesta junto com outros, podendo mesmo ser subjugado por eles. Quando a manifestação do sentimento religioso é colocada sob os auspícios de forças que tentam escravizar os homens, o próprio

\footnotetext{
$9 \quad$ "Si donc il y a dans le cœur de l'homme un sentiment qui soit étranger à tout le reste des êtres vivants, qui se reproduise toujours, quelle que soit la position où l'homme se trouve, n'est-il pas vraisemblable que ce sentiment est une loi fondamentale de sa nature?".

10 "Ce sentiment toutefois s'associe à tous nos esoins, à tous nos désirs".

11 "Le sentiment religieux est une émotion du même genre que toutes nos émotions naturelles; il est, en conséquence, toujours d'accord avec elles."

12 "l'a expérience reposent la religion sur un autre terrain, mais ne la bannissent pas du cœur de l'homme".
} 
sentimento religioso - que sempre se encontra de acordo com o sentimento de liberdade - entra em choque com a religião instituída, que assume formas tirânicas. Liberdade e sentimento religioso teriam, pois, a mesma natureza e um princípio homogêneo ${ }^{13}$. Segundo frisa nosso autor, somente a distinção entre sentimento e forma religiosa podem apontar este movimento. A esse respeito, destaca:

Considerando o sentimento religioso em si mesmo e independente de todas as formas que possa revestir, é evidente que não possui nenhum elemento de escravidáo. A liberdade, a igualdade, a justiça que náo é senão a igualdade, sáo, pelo contrário, seus conceitos favoritos. Criaturas que saem das mãos de um Deus cuja bondade dirige o poder, estando submetidas ao mesmo destino físico e dotadas das mesmas faculdades morais, devem gozar dos mesmos direitos. (Constant de Rebecque, 1999, p. 57) $)^{14}$

É a própria "intuição" da religiosidade (ou do sentimento religioso) que cria os contraditores da religiáo. $\mathrm{O}$ nosso autor, em face desse ponto, argumenta:

em todos os séculos em que os homens tenham reclamado sua independência moral, a resistência para com a religiáo, que pareceu dirigida contra a mais doce das afecçóes, realmente só estava contra a mais opressiva das tiranias.(Constant de Rebecque, 1999, p. 42). ${ }^{15}$

E, mais à frente, completa:

$13 \quad$ Constant de Rebecque, 1999, p. 57. «Prenez à la lettre les préceptes fondamentaux de toutes les religions, vous les trouverez toujours d'accord avec les principes de liberté les plus étendus, on pourrait dire avec des principes de liberté tellement étendus, que, jusqu'à ce jour, l'application en a paru impossible dans nos associations politiques".

14 "En considérant le sentiment religieux en lui-même, et indépendamment de toutes les formes qu'il peut revêtir, il est évident qu’il ne contient nul principe, nul élément d'esclavage. La liberté, l'égalité, la justice, qui n'est que l'égalité, sont au contraire ses conceptions favorites. Des créatures qui sortent des mains d'un dieu dont la bonté dirige la puissance, étant soumises à la même destinée physique, étant douées des mêmes facultés morales, doivent jouir des mêmes droits." Na página 64 encontramos a seguinte passagem: "Telle est donc la tendance invariable du sentiment religieux. C'est entre lui et la liberté, entre l'absence de ce sentiment et la tyrannie qu'existent la nature identique, le principe homogène."

15 "De là, dans tous les siècles où les hommes ont réclame leur indépendance morale, cette résistance à la religion qui a paru dirigée contre la plus douce des affections, et qui ne l'était en effet que contre la plus oppressive des tyrannies". 
O momento em que o sentimento religioso desaparece da alma dos homens está sempre próximo da escravidão. Povos religiosos puderam ser escravos; nenhum povo irreligioso permaneceu livre. A liberdade náo pode estabelecer-se nem conservar-se sem o desinteresse, e qualquer moral alheia ao sentimento religioso só pode fundar-se no cálculo. Para defender a liberdade é preciso saber imolar sua vida. (Constant de Rebecque, 1999, p. 59) ${ }^{16}$

Segundo assevera o pensador, quando do advento da revolução, dizia-se que havia chegado o "triunfo da filosofia incrédula", que foi aceita e professada abertamente. Uma forma de pensamento que surge como reação a uma igreja que se submetia mais aos poderes temporais do monarca do que à crença atemporal da Divindade; uma filosofia que cresceu sustentada pela crítica severa a um corpo clerical, mormente intolerante, que utilizava o poder político que possuía para censurar a liberdade de pensamento ${ }^{17}$. Mais tarde, sob os auspícios da revolução, notadamente durante o período do terror, essa mesma filosofia torna-se, paradoxalmente, fundamento para um governo intolerante que somente aceita a devoção à pátria regrada pela dogmática da religiáo civil. Todavia, a "ausência de qualquer conjectura, de qualquer sentimento, de qualquer esperança religiosa, a incredulidade dogmática, são, pois, impossíveis para o conjunto da espécie humana"18, defende Constant (1999, p. 566). O radicalismo da "filosofia incrédula" serviu para colocar em xeque uma forma estacionária na qual havia se enclausurado o sentimento religioso, para superar um momento no progresso da humanidade. Contudo, um novo sopro de entusiasmo renova os movimentos do sentimento religioso, conforme escreve nosso autor:

\footnotetext{
16 "L’époque où le sentiment religieux disparaît de l'âme des hommes est toujours voisine de celle de leur asservissement. Des peuples religieux ont pu être esclaves; aucun peuple irréligieux n`est demeuré libre. La liberté ne peut s`établir, ne peut se conserver, que par le désintéressement, et toute morale étrangère au sentiment religieux ne saurait se fonder que sur le calcul. Pour défendre la liberté, on doit savoir immoler sa vie".

17 Cf. Constant de Rebecque, 1999, p. 564.São nominalmente citados por Constant, como alvos declarados desse conjunto dominante de clérigos, Rousseau, Montesquieu, Voltaire, Helvetius e Buffon.

18 "Lıabsence de tout conjecture, de tut sentiment, de tout espérance religieuse, lincrédulité, dogmatique sont donc impossibles pour la masse de lespèce humaine.”
} 
Uma agitação misteriosa, um desejo de crer, uma sede de esperança surge por toda parte. Contemplais em toda parte seitas pacíficas, porque o século é pacífico, porém entusiastas, porque a necessidade de entusiasmo é de todos os tempos. Contemplai os metodistas ingleses, os mômiers da Suíça: em Genebra, os moradores de cemitérios, que querem, a qualquer preço, retomar a comunicação com o mundo invisível e o comércio com os mortos; na Alemanha, todas as filosofias impregnadas de misticismo. Mesmo na França, onde a geraçáo mais positiva, apoderando-se da terra parecia, em outros tempos, querer concentrar-se nela, surgem do interior dessa geração, séria e trabalhadora, esforços ilhados, secretos, porém que protestam contra a tendência material, hoje mais tradição do que sistema. (Constant de Rebecque, 1999, p. 565) ${ }^{19}$

Podemos identificar na descrição de Constant uma reação dialética, materialista ou cética-radical às formas estacionárias de religiáo, cuja síntese são novas formas movidas pelo entusiasmo místico. Devido ao apelo místico, essas novas seitas possuem um caráter que Constant denomina de extravagante, mas essa "extravagância" é, para o autor, o sinal de sobrevivência do sentimento religioso. Mas esse impulso místico não se apodera somente das novas formas de religiáo, apodera-se também da literatura, podendo captar nela um anelo religioso. Segundo Constant, a literatura que está sob a influência do sentimento religioso possui uma "meditação imprecisa, sonhadora, cujos olhares se voltam sempre para o futuro sem limites rumo ao infinito. Muitos se perdem nas nuvens; porém seu élan rumo às nuvens é um intento por aproximar-se dos céus." (Constant de Rebecque, 1999 , p. 565 ${ }^{20}$. Ou seja, para o autor, a própria cultura

19 "Mais une agitation mystérieuse, un désir de croire, une soif d'espérer, se manifeste de toutes parts. Partout vous discernez de sectes paisibles, parce que le siècle est paisible, mais enthousiastes, parce que le besoin d'enthousiasme est de touts les temps. Contemplez ces méthodistes anglais, ces mômiers de Suisse ; a Genève, ces habitants de cimetières, voulant à tout prix renouer la communication avec le monde invisible, et le commerce avec les morts ; en Allemagne, touts les philosophes imprégnés de mysticisme. En France même, où la génération la plus positive, s'emparant de la terre, semblait naguère vouloir s'y concentrer, s élèvent, du sein de cette génération sérieuse et studieuse, des efforts isolés, secrétés, mais qui protestent contre la tendance matérielle, tradition aujourd hui, plutôt que système."

20 "La méditation vague, à la rêverie, dont les regardes se tournent toujours vers l'avenir sans bornes et vers l'infini. Beaucoup se perdent dans les nuages; mais leur élan vers les nuages est une tentative pour approcher des cieux." 
romântica nascente, da qual sua obra é parte viva, é um testemunho da existência da religiosidade inata do homem.

Se, por um lado, a revolta contra a petrificação das formas religiosas dá origem a seus opositores, por outro, ela também dá origem àqueles que náo querem o fim das religiốes positivas, mas sim sua "atualização". É do movimento de recusa do sentimento religioso em permanecer estacionário que nascem as chamadas heresias e também os reformadores. Estes últimos, muitas vezes, não querem mais que purificar as crenças tradicionais, suprimindo detalhes que, a seus olhos, contribuiriam para a estagnação do sentimento religioso. Todavia, no conjunto, defenderiam com a própria vida a tradição em que estavam inseridos. No entender de Constant, portanto, os reformadores não seriam "revolucionários", mas sim conservadores não tradicionalistas. Inseridas nas tradiçóes de seu tempo e movidos pelo sentimento religioso, essas pessoas seriam os porta-vozes da necessidade de mudança do status quo.

Ainda conforme Constant, outros dois fenômenos seriam exemplos da relaçáo entre sentimento e forma religiosa, e só por ela poderiam ser explicados. O primeiro é o naturalismo panteísta, descrito pelo autor como "entusiasmo pela natureza, ou pelo grande todo". Esta seria uma forma de manifestação do sentimento religioso dentro do próprio ateísmo. O segundo fenômeno seria o aumento, em força de convencimento e em quantidade, das superstiçóes nos séculos em que os homens de letras optam pelo ceticismo e ironia, sendo as superstiçóes formas grosseiras de expressão do sentimento religioso.

Os equívocos apontados em relação à interpretação da religião teriam se dado, tal como defende nosso autor, porque até então os "filósofos" só haveriam considerado por fora a religião. Os dogmas, as crenças e as práticas cerimoniais, são apenas formas que o sentimento interior assume, temporariamente. Existiriam "leis que guiam a manifestação dessas formas"? Esta é uma pergunta que ninguém tinha examinado, pois a procura da origem da religiâo teria ficado restrita a circunstâncias estranhas ao homem. Tanto o crente quanto o filósofo teriam ficado presos à descrição exterior do "labirinto", 
deixando a história do sentimento religioso por fazer. O grande erro das pesquisas sobre a religiáo foi o mesmo que aconteceu com as demais pesquisas sobre os elementos constitutivos do homem, ou seja, a linguagem e a sociedade. Supôs-se que, em algum momento, o homem pudesse ter existido "sem sociedade, linguagem e religiáo." Supor o homem sem esses três elementos, para Constant, é já não admitir o "homem," uma vez que eles são inerentes ao nosso ser.

Segundo Constant, se formaram três grupos de interpretação do fenômeno religioso, que, por sua natureza e sua origem num tipo especial de intuição, caíram no erro. Para o primeiro grupo, o homem é um ser abandonado à suas próprias forças e a origem do sentimento religioso é algo inacessível. A religião foi comunicada aos seres humanos "por um Ser supremo, de maneira positiva e imutável", e a tentativa de retorno a esse momento originário é uma constante. O "erro" dos adeptos dessa forma de interpretação está em não ver que o progresso é próprio do sentimento religioso, o que torna a obstinação pela volta ao estado de "pureza primitiva", sempre, um esforço infrutífero. $O$ segundo grupo entende a religiáo como um erro vulgar, produzido pelo fundamentalismo e pela intolerância. Para os que defendem essa posição, a religião é reduzida à funçáo de fundamento da moral; logo, concluíram que "seria desejável fundar a moral sobre uma base puramente terrestre e extirpar qualquer sentimento religioso" (Constant de Rebecque, 1999, p. 67 ${ }^{21}$. Conforme acentua Constant, esses filósofos náo conseguiram compreender a necessidade, intrínseca ao ser humano, de crer em algo que transcenda o simplesmente material. Afirma nosso autor que,

se a religião nos é necessária, existe em nós uma faculdade que pede que a exerçamos; se nossa imaginação necessita sair dos limites que nos encerram, se esta parte, sofredora e agitada de nós mesmos, precisa de um mundo do qual possa dispor e embelezar a seu gosto, seria inútil que se reprovasse a religiáo por seus inconvenientes e seus perigos.

$21 \quad$ "Il en a conclu quil serait désirable de fonder la morale sur une base purement terrestre, et d)extirper tout sentiment religieux." 
A necessidade vencerá sempre a prudência. (Constant de Rebecque, 1999, p. 67) ${ }^{22}$

O terceiro grupo, tentando se colocar como meio termo, criou a ideia de religião natural. Assim como os ortodoxos do primeiro grupo e os incrédulos do segundo, estes também supuseram que o homem poderia, de posse da verdade absoluta, criar dogmas da razão atemporais e imutáveis. Buscaram uma utilidade imediata para a religiáo, ao tentar conservar apenas os princípios racionais, que servem de base a todas as religióes. Os homens que formularam a religião natural teriam considerado os ditos princípios racionais de um ponto de vista reducionista, como substitutos das leis penais. Este enfoque acarreta mais de um inconveniente, a saber:

Buscar em todas as belezas da natureza um uso imediato, uma aplicação direta à vida em comum, desaparece todo o charme de seu conjunto, do mesmo modo, nunca perdendo de vista que a religião deve ser útil, se degrada a religião; em segundo lugar, ao não implicar a utilidade prática a verdade da teoria, o homem não é mais religioso, porque se lhe diz que a religião é útil, porque não acreditamos em um objetivo; finalmente, a utilidade da religiáo serve como pretexto para aqueles que governam violentar à consciência daqueles que são governados. (Constant de Rebecque, 1999, p. 70) ${ }^{23}$

Dada essa argumentação, qual seria, então, a posição de nosso autor frente aos problemas levantados? É a partir do problema da revelação que podemos encontrar a resposta para essa pergunta. Para ele, a origem da religião é a "revelação interna”, cuja fonte

$22 \quad$ "Sill existe en nous une faculté qui demande à s’exercer, si notre imagination a besoin de sortir des limites qui nous renferment, ssil faut à cette partie souffrante et agitée de. nousmêmes un monde dont elle dispose et quelle embellisse à son gré, ce serait bien en vain qu on reprocherait à la religion ses inconvénients ou ses périls. La nécessité vaincra toujours la prudence."

23 "Comme en cherchant dans toutes les beautés de la nature un usage immédiat, une application directe à la vie commune, on flétrit tout le charme de son magnifique ensemble, de même en ne perdant jamais de vue que la religion doit être utile, on dégrade la religion en second lieu, l`utilité pratique nimpliquant nullement la vérité de la théorie, l’homme n`en est pas plus religieux parce qu>on lui dit que la religion est utile, car on ne croit pas dans un but; enfin, lıutilité de la religion sert de prétexte à ceux qui gouvernent pour faire violence aux consciences de ceux qui sont gouvernés." 
está no próprio coração do homem, sendo, portanto, uma forma universal de revelação. Mas haveria, para nosso autor, um lugar para a revelação "sobrenatural"? Sim, pois o pensador franco-suíço não deseja negar esta possibilidade. No entender de Constant, o que há é uma relação entre o sentimento interior e a circunstância exterior. Acentua Constant que:

Temos de notar que, quando dizemos que o sentimento interior assume uma forma e logo a abandona, não colocamos em dúvida que esta forma não possa lhe ser apresentada de uma maneira sobrenatural, quando a assume e que da mesma maneira, não seja capaz de se emancipar dela de uma maneira sobrenatural, quando ele a deixa. [...]. Afirmar que o germe da religiáo está no coração do homem, não é certamente dar a este dom do céu uma origem puramente humana. $\mathrm{O}$ ser infinito depositou este germe em nosso interior para nos preparar às verdades que devíamos conhecer. Paulo diz que Deus deixou, até certa época, que as naçóes o procurassem por suas próprias forças. Quanto mais convencidos estivermos de que a religiáo foi nos revelada através de modos sobrenaturais, mais teremos de admitir que teríamos em nós a faculdade de receber estas comunicaçóes maravilhosas. É a esta faculdade que nós nomeamos sentimento religioso. (Constant de Rebecque, 1999, p. 581-582) ${ }^{24}$

A única forma de encontrarmos o sentimento religioso destituído de sua forma histórica, ou seja, fora da relação descrita no trecho supracitado, é pelo pensamento. Mas, como afirma o próprio escritor, o objetivo de sua obra não é indagar sobre "a origem desta disposição que faz do homem um ser duplo e enigmático"(Constant de Rebecque, 1999, p. 50) ${ }^{25}$.

$24 \quad$ "Nous devons remarquer qu'en disant que le sentiment intérieur prend une forme et la brise ensuite, nous ne contestons point que cette forme ne puisse lui être présentée d'une manière surnaturelle quand il la reçoit, et qu'il ne puisse de même en être affranchi d'une manière surnaturelle quand il la brise. [...].Affirmer que le germe de la religion se trouve dans le cœur de l'homme, ce n'est assurément point assigner à ce don du ciel une origine purement humaine. L'être infini a déposé ce germe dans notre sein, pour nous préparer aux vérités que nous devions connaître. Paul, qui dit que Dieu avait laissé, jusqu’à une certaine époque, les nations le chercher par leurs propres forces. Plus on est convaincu que la religion nous a été révélée par des voies surnaturelles, plus on doit admettre que nous avions en nous la faculté de recevoir ces communications merveilleuses. C'est cette faculté que nous nommons le sentiment religieux".

25 Cf. Constant de Rebecque, 1999, p. 50. 
Constant opta, portanto, por uma "epistemologia modesta", que aceita a possibilidade da existência numenica do sentimento religioso como fundamento das religióes constituidas, mas que não objetiva ir além da realidade histórica. E, embora não possamos separar o sentimento da forma, uma vez que o primeiro não existe sem a segunda, podemos, pelo esforço da razão, descartar aquilo que é variável, segundo situaçôes e circunstâncias temporais, e reunir aquilo que é invariável e imutável, concebendo uma estrutura que caracterize esse sentimento universal. Acentua Constant que:

Pelo simples fato de que este sentimento guarda importância e proporção em todos os estados, em todos os séculos e com todas as concepçôes, as aparências que o revestem são frequentemente grosseiras. Mas, apesar dessa deterioração exterior, se encontram sempre, nelas, sinais que o caracterizam e o dão a conhecer. (Constant de Rebecque, 1999, p. 51) ${ }^{26}$

Por analogia, resta a Constant colocar este sentimento na mesma categoria das emoçóes; todavia, como ele mesmo alerta, em um plano superior. Justamente por essa tomada de posição metodológica, o autor considera que as possíveis acusaçóes contra sua definição de sentimento religioso como sendo obscura e vaga são injustas.

Restaria, pois, o esforço de estudar a história das religiōes para distinguir o sentimento religioso das formas religiosas, e então podermos compreender a História da Religião. Alerta nosso autor para o fato de que, se náo se admite a existência do sentimento religioso como uma espécie de a priori, fica impossível explicar a origem das ideias religiosas. E, embora afirme a impossibilidade de conhecer o sentimento religioso separado de suas formas manifestas ${ }^{27}$, Constant sugere que o sentimento "nasce da necessidade que tem o homem de colocar-se em contato com os poderes invisíveis" e que a forma nasce da necessidade que os seres humanos têm de

26 "Par cela même que ce sentiment se proportionne à tous les états, à tous les siècles, toutes les conceptions, les apparences qu'il revêt sont souvent grossières. Mais en dépit cette détérioration extérieure, on retrouve toujours en lui des traits qui le caractérisent et le font reconnaître."

$27 \quad$ Frisa o autor que, "La masse des hommes prend la religion comme elle se présente; pour elle, la forme est le fonde". Constant de Rebecque, 1999, p. 90-91. 
comunicar, de maneira regular e permanente, os meios pelos quais se estabelece esse contato. A respeito disso, afirma: "a consagração desses meios, sua regularidade e sua permanência são coisas das quais não se pode prescindir"no estabelecimento das religióes positivas. Essa necessidade de comunicar é parte essencial da destinação do humano, que está fadado a existir junto a seus semelhantes e que só pode desfrutar de seu próprio sentimento quando este se vincula com o que ele denomina de "sentimento universal". Em resumo, é do imperativo da vida em comunidade que nascem as formas positivas de religião, segundo nosso autor, proporcionais ao estado de cada época da humanidade ${ }^{28}$. As formas positivas de religião nascem para satisfazer uma necessidade do homem, porém, alerta Constant que

Por satisfatória que seja para o presente [a forma positiva de religião], contém um germe de oposição aos progressos do futuro. Assume, pelo fato mesmo de sua duração, um caráter dogmático e estacionário que se resiste a seguir a inteligência em suas descobertas e a alma em suas emoçôes, que a cada dia tornam-se mais refinadas e mais delicadas. (Constant de Rebecque, 1999, p. 53) ${ }^{29}$

A necessidade de manter seus seguidores faz com que as religióes se utilizem de imagens cada vez mais materializadas, assemelhando "o mundo dos poderes invisíveis" ao mundo ordinário.

As ideias que [a forma religiosa] sugerem se fazem cada vez mais limitadas, como as ideias terrestres, das quais são apenas cópias, e chega a época em que elas só oferecem ao espírito afirmaçóes que este não pode admitir e à alma práticas que não a satisfazem. O sentimento religioso se separa desta forma, por assim dizer, petrificada. Reclama outra [forma] que não o agrida, e não para até encontrá-la. (Constant de Rebecque, 1999, p. 53) ${ }^{30}$

28 Cf. Constant de Rebecque, 1999, p. 52-53. Se lembrarmos que para Constant linguagem, sociedade e religiosidade são as características fundamentais do homem, e que este nunca existiu sem nenhuma dessas três formas de ser, devemos concluir que: sempre houve, em qualquer época da humanidade, um tipo positivo de religião.

29 "Mais toute forme positive, quelque satisfaisante qu'elle soit pour le présent, contient un germe d'opposition aux progrès de l'avenir. Elle contracte, par l'effet même de sa durée, un caractère dogmatique et stationnaire qui refuse de suivre l'intelligence dans ses découvertes, et l'âme dans ses émotions que chaque jour rend plus épurées et plus délicates."

30 "Forcée, pour faire plus d'impression sur ses sectateurs, d'emprunter des images presque matérielles, la forme religieuse n'offre bientôt plus à l'homme fatigué de ce monde qu'un 
Quando uma nova forma menos materializada de religiáo aparece, a opiniáo pública a adota como uma verdade e a moral se une a ela. Até mesmo as autoridades, representantes do status quo, que a princípio resistem ao seu aparecimento, com o tempo aderem à forma de vida que a nova religiáo origina. "Isto é, com efeito, o que acontece com o aparecimento da religiáo cristã. O sentimento religioso se apodera dessa forma depurada; sua parte vaga, melancólica e comovedora encontra refúgio nela". Sugere Constant que as religiôes anteriores ao cristianismo teriam se elevado da terra ao céu construindo sua fundamentação em bases materiais, o que fez com que sua base se desmoronasse. Já o cristianismo faria o movimento contrário: transladando sua base para algo menos material, traria o céu para a terra ${ }^{31}$.

Explicando seu método, Constant deixa claro que, em primeiro lugar, é preciso demonstrar respeito em relação a tudo que afeta a religiấo. Só com tal atitude é possível uma aproximação que nos permita ver além dos fatos superficiais, e quando conseguimos isso, percebemos que o sentimento religioso é uma qualidade inerente ao homem, sendo parte constitutiva de nossa natureza. A partir do reconhecimento desse sentimento, é possível fazer um estudo até certo ponto imparcial do fenômeno religioso, percebendo as particularidades de cada manifestação como algo superficial e situacional. Assim como progridem as sociedades, também as formas de manifestação religiosa progridem. Este é, conforme nosso autor, seu primeiro princípio. A partir dele, Constant parte para a formulaçấo de etapas de progressão e chega à conclusão de que a aparição de cada forma religiosa se dá em três períodos, como uma espécie de movimento dialético.

O primeiro momento é aquele mais primitivo, em que o homem trava suas primeiras relaçôes com os poderes invisíveis. Depois de

monde à peu près semblable. Les idées qu'elle suggère deviennent de plus en plus étroites, comme les idées terrestres dont elles ne sont qu'une copie, et l'époque arrive, où elle ne présente plus à l'esprit que des assertions qu'il ne peut admettre à l'âme que des pratiques qui ne la satisfont point. Le sentiment religieux se sépare alors de cette forme pour ainsi dire pétrifiée. Il en réclame une autre qui ne le blesse pas, et il s'agite jusqu'à ce qu'il l'ait trouvée."

31 Cf. Constant de Rebecque, 1999, p. 57-58. Trataremos desse tema, de forma específica, mais a frente. 
estabelecidas as relaçóes, ele procura lhe dar uma forma determinada e regular. O segundo momento se dá quando as demais faculdades, isto é, a razão, se desenvolve. A partir deste ponto, há um embate natural entre o que aponta o progresso obtido pela racionalidade e as religióes instituídas. Conforme acentua nosso autor;

se, como ocorre na natureza das coisas, a queda da antiga crença é adiada por parte das instituiçôes, essa prolongação fictícia só produz para os seres humanos uma existência de puro mecanismo, em que tudo parece sem vida. $\mathrm{O}$ entusiasmo e a crença abandonam a religiáo. Só há fórmulas, práticas e sacerdotes. (Constant de Rebecque, 1999, p. 80$)^{32}$

Surge então o terceiro momento, que é aquele em que o próprio sentimento religioso entra em choque com as religióes instituídas. A propósito, destaca nosso autor:

Esta luta introduz a terceira época, a aniquilação da forma rebelde, e daí vêm às crises de incredulidade completa, crises desordenadas e, às vezes, terríveis, mas inevitáveis, quando o homem deve se livrar daquilo que, agora, só lhe seria um obstáculo. Essas crises são sempre seguidas por uma nova forma de ideias religiosas, melhor adaptadas às faculdades do espírito humano, e a religião sai mais rejuvenescida, mais pura e mais bela das cinzas. (Constant de Rebecque, 1999, p. $80)^{33}$

Para compreender esse movimento, afirma Constant, foi necessário remontar a um estado menos avançado da civilizaçáo humana, ao qual o autor denomina de "estado selvagem". Mas, o que entende o pensador franco-suíço por "selvagem”? Ao contrário de alguns filósofos do século XVII e XVIII, que entendiam o estado selvagem como aquele em que se encontrou a espécie humana em

32 "Si, comme il est dans la nature des choses, la chute de la croyance vieillie est retardée par des institutions, cette prolongation factice ne produit pour lespèce humaine qu>une existence de pur mécanisme, durant laquelle tout semble privé de vie. L`enthousiasme et la croyance délaissent la religion; II n'y a plus que des formules, des pratiques et des prêtres."

33 "Cette lutte amène la troisième époque, lranéantissement de la forme rebelle, et de là les crises dincrédulité complète, crises désordonnées et quelquefois terribles, mais inévitables, quand l'homme doit être délivré de ce qui ne lui serait désormais qu^une entrave. Ces crises sont toujours suivies d)une forme didées religieuses, mieux adaptée aux facultés de liesprit humain, et la religion sort plus jeune, plus pure et plus belle de ses cendres. » 
sua origem, Constant náo objetiva encontrar o estado do "bom selvagem" ou do "homem simples e ignorante" dos contratualistas. Nosso autor não considera "o estado selvagem como aquele em que se encontrou a espécie humana em sua origem". Ou seja, para cada sociedade existe um período ao qual se pode denominar de selvagem, ainda que não de forma absoluta. E no que tange à religião, o método proposto por Constant não pretende determinar como ela começa a se manifestar positivamente, ou seja, como se dá seu início primevo, mas "só de que maneira esta, no estado mais rudimentar que se pode pensar, se levanta e chega a noçóes mais puras" ${ }^{3}$.

\section{Referências bibliográficas}

CONSTANT DE REBECQUE, Benjamin.De la religion considérée dans sa source, ses formes et ses développements. Paris: Bossage, 1824-1836.

. De la religion. Arles: Actes Sud, 1999.

. Du polytheisme romain. Paris: Béchet Aine Libraire, 1833.

DEGUISE, Pierre. Benjamin Constant meconnu - le livre "De la religion ". Geneve: Droz, 1966.

GOUHIER, Henri. Benjamin Constant devant la religion. Paris: Desclee de Brouwer, 1967.

KLOOCKE, Kurt. Benjamin Constant, une biographie intelectuelle. GeneveParis: Droz, 1984.

- Les écrits de Benjamin Constant sur la religion: quelques réflexions herméneutiques et méthologiques. Cahiers de l'Association internationale des études francaises, vol. 48, n. 1, Année 1996,p. 391-405.

. Benjamin Constant et l'Allemagne: individualité - religion- politique. AnnalesBenjamin Constant, n. 27, Lausanne, 2003, p.127-171.

. Johann Gottfried Herder et Benjamin Constant .Annales Benjamin Constant, n. 29, Lausanne, Anné 2005a, p.55-72.

34 Cf. Constant de Rebecque, 1999, p. 86-88. 
. L'idée de l'individualité dans les écrits politiques de Benjamin Constant. Annales Benjamin Constant, n. 29, Lausanne, Anée 2005b, p.143-158.

- Benjamin Constant et l'Allemagne. Oeuvres et critiques : revue international d'etude de la reception critique des oeuvres litteraires de langue francaise, n. 33, Anné 2008, p.19-38.

WACH, Joachim. El estudio comparado de las religiones. Buenos Aires: Paidos, 1967.

\section{[Endnotes]}

1 Pienso aquí, por ejemplo, en los estudios de género, los cuales distinguen el sexo biológico (dimensión IO) de la identidad psicosexual (dimensión IS), a la vez que analizan las diferentes representaciones culturales acerca de la esfera masculina y femenina (dimensión CS), y de cómo aquellas ideas han legitimado diversos tipos de roles y relaciones económicas y políticas (dimensión CO). Otro ejemplo que puede dar testimonio de una división cuadripartita de su unidad de análisis es el de la antropología de la salud, la cual diferencia el organismo biológico afectado por alguna patología (dimensión IO), de la enfermedad como una experiencia biográfica e identitaria individual (dimensión IS). A su vez, este campo de estudio se ocupa de las diversas representaciones sobre la salud y la enfermedad, su etiología y su tratamiento (CS), así como del rol del enfermo en la sociedad, su posición dentro del modo de producción y los factores económicos, políticos y sociales que inciden en el proceso de medicalización de determinados padecimientos (dimensión CO).

2 Este autor delimita dicho campo de estudios desde las primeras páginas de su clásica obra, Las variedades de la experiencia religiosa, con las siguientes palabras: "He de advertir que no soy un teólogo, ni un erudito en historia de las religiones, ni siquiera un antropólogo. La psicología es la única rama del saber en la que estoy especializado, y para un psicólogo las tendencias religiosas del hombre deben ser como mínimo tan interesantes como cualquiera de las distintos hechos que forman parte de su estructura mental (...) Cuando la investigación es de orden psicológico, el tema de la misma no puede ser la institución religiosa, sino más los sentimientos e impulsos religiosos; habré de ceñirme, pues, a aquellos fenómenos subjetivos más desarrollados que algunos hombres inteligentes y conscientes de sí mismos dejaron registrados en sus testimonios autobiográficos" (James, 1988, p. 14).

3 A propósito de ello, Manuela Cantón remarca: "Benedict, contemporánea de Lowie y Radin, practicó también un enfoque psicológico que, aunque más orientado en apariencia a la cultura que a los individuos, le llevó a definir las culturas de las que se ocupó a partir de tipos psicológicos de personalidad” (Cantón, 2009, p. 135). 
4 En este sentido, destaca el trabajo de Belzen, un representante actual del campo de estudios conocido como Psicología Científica de la Religión, cuya meta es "fazer uso de instrumentos psicológicos (teorias, conceitos, intuiçóes, métodos e técnicas) para analisar e entender a religiáo" (Belzen,2009, p. 2).

5 Cf. Widengreen (1976) para una exposición introductoria de los principales temas y autores de la fenomenología de la religión y Usarski (2004) para una síntesis critica de esta rama de estudios.

6 Entendido como un sistema de disposiciones adquiridas por medio del aprendizaje implícito o explícito, que funciona como generador de categorías de percepción, evaluación, apreciación, y también como principios organizadores de la acción (Bourdieu, 2007, p. 85-89).

7 Definido por el sociólogo francés como "una red o una configuración de relaciones objetivas entre posiciones. Estas posiciones están objetivamente definidas, en su existencia y en las determinaciones que imponen sobre sus ocupantes, agentes e instituciones, por su situación presente y potencial (situs) en la estructura de distribución de especies de poder (capital) cuya posesión ordena el acceso a ventajas específicas que están en juego en el campo, así como por su relación objetiva con otras posiciones (dominación, subordinación, homología, etcétera)" (Bourdieu y Wacquant, 2005, p. 150).

8 Para poner un ejemplo, Elias en su "teoría de la civilización" analiza en profundidad la forma en que los cambios en las estructuras sociales humanas se transforman en cambios en las estructuras psíquicas, debido a la interrelación de los individuos y la internalización de los controles, de forma que la diferenciación de la sociedad deviene en una transformación del comportamiento en el sentido de una regulación cada vez más diferenciada del aparato psíquico (Elias, 1987).

9 A propósito de esto, hay que reconocer la visión pionera de Weber, quien otorga un lugar de relevancia a las características psicológicas -ya sean emocionales o intelectuales- de los bienes de salvación: "el valor sagrado ha sido, primordialmente, un estado terreno y actual. Este estado radica esencialmente en la actitud emotiva por sí misma, inducida de manera directa por el acto específicamente religioso o mágico, por la disciplina ascética o por la contemplación” (Weber, 1996, p. 22).

10 En cierta forma, Ricoeur (1994) ha expresado alguno de estos roles que la dimensión CS juega al proponer que la imaginación cultural, también entendida como los procesos simbólicos de la sociedad, presenta un polo ideológico y un polo utópico. El ideológico se encuentra vinculado con tres funciones sociales. Primero, con la manipulación de la conciencia social, en el sentido de proporcionar una imagen invertida de la realidad. Segundo, con la legitimación de un orden social y 
de una estructura de autoridad determinada. Tercero, la función más elemental de la ideología, previa a las anteriores, es la de integración, ya que las representaciones compartidas constituyen el marco simbólico con el cual se construye la identidad de un grupo. El polo utópico de la imaginación cultural es el que posibilita repensar el orden social existente. Desde el "no lugar" que por definición implica la utopía, es posible efectuar una mirada crítica a la propia sociedad 